\title{
Ambient air pollution and pediatric diabetes
}

Jae Hyun Kim, MD, PhD ${ }^{1,2}$

${ }^{1}$ Department of Pediatrics, Seoul National University Bundang Hospital, Seongnam, Korea; ${ }^{2}$ Department of Pediatrics, Seoul National University College of Medicine, Seoul, Korea

\section{Key message}

- Epidemiological studies have shown that ambient air pollution is associated with diabetes mellitus in children and adults.

- The mechanism of ambient air pollution causing diabetes mellitus is unclear.

- A study of the association between diabetes and air pollution in Korean pediatric populations is required.

Air quality is a critical issue in public health because of its impact on the human body. Ambient air pollution is associated with an increased risk of respiratory, cardiovascular, and infectious diseases as well as increased mortality. ${ }^{1}$ Moreover, epidemiologic studies have reported that ambient air pollution is associated with diabetes mellitus.

A recent meta-analysis revealed that exposure to ambient air pollution is related to type 2 diabetes (T2D) in adults. ${ }^{2)}$ Particulate matter $\leq 2.5 \mu \mathrm{m}\left(\mathrm{PM}_{2.5}\right)$ and $\leq 10 \mu \mathrm{m}\left(\mathrm{PM}_{10}\right)$ in diameter are significantly associated with an increased incidence and prevalence of T2D. Nitrogen dioxide $\left(\mathrm{NO}_{2}\right)$ is associated with an increased prevalence of T2D.

However, in the pediatric population, a direct association between ambient air pollution and T2D has not yet been reported. In a German study, exposure to traffic-related $\mathrm{NO}_{2}$ and $\mathrm{PM}_{10}$ at birth is associated with insulin resistance at 10 years of age. ${ }^{3)}$ In overweight and obese pediatric populations, exposure to $\mathrm{NO}_{2}$ and $\mathrm{PM}_{2.5}$ accelerated the decrease in insulin sensitivity and beta cell function at the age of 18 years, which might increase the risk for T2D. ${ }^{4)}$ The exact mechanism by which air pollution increases the T2D incidence remains to be clarified. Systemic inflammation, oxidative stress, endoplasmic reticulum stress, mitochondrial dysfunction, and epigenetic changes are proposed possible mechanisms. ${ }^{5)}$

In the pediatric population, several reports have revealed an association between air pollution and the incidence of type 1 diabetes (T1D). Hathout et al. ${ }^{\circ}$ reported that exposure to ozone and sulfate in ambient air is associated with the development of T1D in children. An environmental-wide association study performed in England revealed that several air pollutants, including $\mathrm{PM}_{10}, \mathrm{NO}_{2}$, nitrogen oxides, and carbon monoxide, were associated with the risk of T1D in children.") Moreover, Elten et al. ${ }^{8)}$ showed that ozone exposure during the first trimester of pregnancy was associated with an increased incidence of T1D at an early age.

Choi et al. ${ }^{9)}$ recently reported an association between air pollutant emissions and the incidence of T1D in the Russian Federation. The amount of air pollutants was significantly associated with the incidence of both T1D and T2D in Russia in 2016-2017. Although the detailed pollutants were not specified, a positive correlation was observed.

The incidence of T1D and T2D in pediatric patients has increased worldwide and in Korea over the past several decades. An increase in the incidence of T2D in youth is related to an increase in obesity. The reason for the increasing incidence of pediatric T1D is not fully understood. However, if there was no significant change in population structure, environmental factors might play a significant role in the development of both types of diabetes mellitus in childhood.

Environmental factors may play a significant role in the development of diabetes in childhood. Long-lasting exposure to ambient air pollution is a critical environmental factor. Further research is required to investigate which pollutants are related to an increased incidence of diabetes in childhood, clarify the mechanism involved in the development of diabetes, and identify the critical time for detrimental metabolic effects of ambient air pollution. Moreover, epidemiologic studies are needed in Korean children and adolescents.

\section{Footnotes}

Conflicts of interest : No potential conflict of interest relevant to this article was reported.

See the article "Correlation between total air pollutant emissions and incidence of type 1 diabetes in the Russian Federation" via https://doi.org/10.3345/cep.2020.01501. 


\section{References}

1. Manisalidis I, Stavropoulou E, Stavropoulos A, Bezirtzoglou E. Environmental and Health impacts of air pollution: a review. Front Public Health 2020;8:14.

2. Yang BY, Fan S, Thiering E, Seissler J, Nowak D, Dong GH, et al. Ambient air pollution and diabetes: a systematic review and meta-analysis. Environ Res 2020;180:108817.

3. Thiering E, Cyrys J, Kratzsch J, Meisinger C, Hoffmann B, Berdel D, et al. Long-term exposure to traffic-related air pollution and insulin resistance in children: results from the GINIplus and LISAplus birth cohorts. Diabetologia 2013;56:1696-704.

4. Alderete TL, Habre R, Toledo-Corral CM, Berhane K, Chen Z, Lurmann $\mathrm{FW}$, et al. Longitudinal associations between ambient air pollution with insulin sensitivity, beta-cell function, and adiposity in Los Angeles Latino children. Diabetes 2017;66:1789-96.

5. Franklin BA, Brook R, Arden Pope C 3rd. Air pollution and cardiovascular disease. Curr Probl Cardiol 2015;40:207-38.
6. Hathout EH, Beeson WL, Ischander M, Rao R, Mace JW. Air pollution and type 1 diabetes in children. Pediatr Diabetes 2006;7:81-7.

7. Sheehan A, Freni Sterrantino A, Fecht D, Elliott P, Hodgson S. Childhood type 1 diabetes: an environment-wide association study across England. Diabetologia 2020;63:964-76.

8. Elten M, Donelle J, Lima I, Burnett RT, Weichenthal S, Stieb DM, et al. Ambient air pollution and incidence of early-onset paediatric type 1 diabetes: a retrospective population-based cohort study. Environ Res 2020;184:109291.

9. Choi HS, Kim JT, Seo JY, Linkov F, Shubnikov E, Lee HK. Correlation between total air pollutant emissions and incidence of type 1 diabetes in the Russian Federation. Clin Exp Pediatr 2021;63:525-30.

How to cite this article: Kim JH. Ambient air pollution and pediatric diabetes. Clin Exp Pediatr 2021;63;523-4. https://doi. org/10.3345/cep.2021.00122 